\title{
Evaluation of Some Finishing Properties of Oil Palm Particleboard for Furniture Application
}

\begin{abstract}
The finishing properties of particleboard made from the Empty-Fruit Bunch (EFB) of oil palm (Elaeis guineensis Jacq.) were evaluated for its suitability for furniture applications, using different coating and overlay materials. The results found that the thick plastic-formica overlay provided the best surface finish, in terms of surface smoothness, adhesion strength and impact resistance. Although the polyurethane lacquer provided an acceptable finish, its quality and performance is not comparable to that of the thick plastic overlay. Despite the fact that the use of such overlay material may render the material not aesthetically appealing and limit it to concealed applications or where the thick overlay material is tolerated, its cost competitiveness and environmental friendliness may be able to position the oil palm particleboard as a substitute for the conventional wood-based particleboard in the furniture manufacturing industry.
\end{abstract}

Keyword: Finishing, Properties, Oil Palm, Particleboard, Furniture 